\title{
Práticas de letramento crítico na formação de professores de línguas estrangeiras
}

\section{Critical literacy practices in foreign language teachers Education}

\author{
Elzimar Goettenauer de Marins Costa* \\ Universidade Federal de Minas Gerais \\ Belo Horizonte - Minas Gerais / Brasil
}

But what is literacy? Once we answer this question, the [...] teacher's role becomes even more crucial and yet at the same time much more problematic.

James Paul Gee

\begin{abstract}
RESUMO: O MEC vem nos últimos anos investindo em medidas que visam a dar um norte ao ensino regular, tomando como base estudos acadêmicos desenvolvidos no âmbito do ensino e da aprendizagem e levando em consideração as mudanças socioculturais geradas pela globalização e pelo avanço da tecnologia. Constata-se, no entanto, uma defasagem entre as concepçôes de educação e de linguagem subjacentes aos PCN, às OCEM e a outras iniciativas, como o PNLD, por exemplo, e sua implementação posta em prática na Educação Básica. No caminho a ser trilhado para diminuir essa defasagem, uma questão crucial se impõe: as concepções teórico-metodológicas que fundamentam as referidas iniciativas precisam repercutir significativamente na formação inicial e continuada para poderem repercutir na atuação dos professores na sala de aula do ensino regular. Partindo desse pressuposto, discuto neste artigo as implicações da incorporação de práticas de letramento crítico na formação inicial de professores de línguas estrangeiras.
\end{abstract}

PALAVRAS-CHAVE: línguas estrangeiras, formação inicial, letramento crítico.

ABSTRACT: The Ministry of Education has been investing on measures which attempt at guiding regular school teaching, taking into account academic studies developed in the teaching and learning area as well as the socio-cultural changes generated by globalization and technological advances. In spite of that, it is observed that there is a gap between the conceptions of education and language matters in the National Curricular Parameters (PCN), the Curricular Guidance for Secondary School (OCEM) and other initiatives, such as the National Plan for Didactic Books (PNLD), for example, and its implementation in Primary Education. In

* elzimarc@gmail.com 
the path to be followed towards diminishing this gap, a crucial issue is raised: the theoretical-methodological conceptions which set up the referred initiatives must reverberate meaningfully in initial and continuing education in order for them to do so in the performance of teachers in regular school classrooms too. Therefore, starting from this assumption, this article aims at discussing the dilemmas and the implications of the incorporation of critical literacy practices in the initial education of foreign language teachers.

KEYWORDS: foreign languages, initial education, critical literacy.

\section{Introdução}

O MEC, por meio de suas secretarias, vem nos últimos anos investindo em medidas que visam a dar um norte ao ensino regular, buscando referências nos estudos acadêmicos desenvolvidos no âmbito do ensino e da aprendizagem e levando em consideração as mudanças socioculturais geradas pela globalização e pelo avanço da tecnologia. Dentre essas medidas, podemos mencionar não só a publicação de parâmetros e orientações, mas também o fortalecimento de ações como o Programa Nacional do Livro Didático (PNLD), por meio da definição de critérios de seleção de materiais didáticos pautados em concepções teórico-metodológicas contemporâneas, a inclusão da língua estrangeira (LE) nos editais do PNLD 2011 e 2012, a criação do Programa Nacional Biblioteca da Escola (PNBE) em 1997 e a publicação da Coleção Explorando o Ensino.

As Orientaçôes Curriculares para o Ensino Médio (OCEM), publicadas em 2006, ressaltam o objetivo de preparar o jovem para a sociedade complexa na qual vivemos, em consonância com o artigo 35 da LDB (no 9.394; BRASIL, 1996), que atribui as seguintes finalidades ao ensino médio: "o aprimoramento do educando como ser humano, sua formação ética, desenvolvimento de sua autonomia intelectual e de seu pensamento crítico, sua preparação para o mundo do trabalho e o desenvolvimento de competências para continuar seu aprendizado". O documento retoma também alguns dos princípios expostos anteriormente nos Parâmetros Curriculares Nacionais para o Ensino Fundamental (PCN-EF) (BRASIL-SEF, 1998) e nos Parâmetros Curriculares Nacionais para o Ensino Médio (PCN-EM) (BRASIL-SEB, 1999) e, com relação ao ensino/aprendizagem de LE, assinala seu papel educativo e sua função de contribuir para a formação do cidadão e para os projetos de inclusão. No que se refere aos pressupostos teóricometodológicos, dá ênfase à heterogeneidade da linguagem e da cultura, ao multiletramento, à multimodalidade e ao letramento crítico. 
Por sua vez, os critérios de avaliação divulgados nos editais do PNLD 2011 e do PNLD 2012 de LE e as respectivas fichas usadas na análise e seleção dos livros didáticos inscritos corroboram a perspectiva adotada nos documentos mencionados quanto ao papel e a importância da LE na educação básica: formação da cidadania, desenvolvimento da autonomia intelectual e da reflexão crítica, construção coletiva do conhecimento.

Passados mais de dez anos da publicação dos PCN de LE para o Ensino Fundamental e Médio, e mais de cinco anos da publicação das OCEM, observa-se que ainda são incipientes a discussão e a implementação dos pressupostos teórico-metodológicos desses documentos na licenciatura em LE. O avanço acelerado das Tecnologias de Informação e Comunicação (TIC), por exemplo, impõe desafios:

São desafios na medida em que a questão ainda não entrou de fato na pauta das discussões institucionais sobre renovação do ensino da língua e, no caso da formação em Letras, tem sido mantida à margem ou completamente ausente em grande parte, senão na maioria das instituições. (SIGNORINI; FIAD, 2012, p. 9-10)

No contexto desta discussão, as constatações de Walkyria Monte Mór, após realizar uma pesquisa para "compreender as construçôes de sentidos dos graduandos de Letras em atividades acadêmicas voltadas para a interpretação" (2012, p. 173), são reveladoras. O estudo apontou para a dificuldade dos alunos em romper com uma forma interpretativa tradicional, embora os textos escolhidos possibilitassem essa ruptura, e a pesquisadora observa que uma possibilidade para tal dificuldade

remeteria ao tipo de trabalho pedagógico realizado nas escolas e universidades brasileiras, que, em grande parte, seguem uma orientação hermenêutica tradicional [...] e uma epistemologia convencional. Nesta, a construção do conhecimento tende a ocorrer de forma compartimentada, fragmentada em subáreas de conhecimento. Essa perspectiva leva os aprendizes a organizar os conhecimentos de forma não transdisciplinar, uma organização que dificulta o fluxo de conhecimentos, experiências ou vivências de um compartimento para outro. (MONTE MÓR, 2012, p. 178)

No âmbito da formação de professores de língua, nos defrontamos com a diversidade de currículos, a relativa autonomia dos docentes para propor ementas e programas e, ainda, com a tendência a relegar às disciplinas de Prática 
de Ensino e Estágio Supervisionado as questōes relacionadas a ensino e aprendizagem. Devido a tais fatores, torna-se difícil empreender mudanças que afetem globalmente a licenciatura. No entanto, parece ser coerente supor que as concepçôes teóricas e metodológicas preconizadas pelos documentos oficiais só serão de fato incorporadas à Educação Básica se, de alguma maneira, fizerem parte das políticas de formação de professores, não só a continuada, mas também a inicial.

As iniciativas governamentais podem contribuir para dar novos rumos à educação e à escola, mas elas não surtem efeito automaticamente. Isso quer dizer que a publicação e a eventual leitura dos documentos publicados pelas secretarias do MEC, assim como a adoção dos livros didáticos selecionados pelo PNLD, não são suficientes para que novas concepções de linguagem, ensino e aprendizagem sejam postas em prática nas salas de aula do ensino regular.

A publicação de livros destinados a apresentar modos de converter a teoria em prática, como o de Rojo (2000), por exemplo, contribui para indicar ao professor alguns caminhos a seguir na aplicação dos parâmetros e das orientações, contudo, grande parte dos docentes do ensino fundamental e médio, por diversas razões, não tem acesso a esses livros. Portanto, no percurso a ser trilhado para diminuir o descompasso entre o que é proposto e o que se faz na Educação Básica, uma questão crucial se impõe: as concepções teóricometodológicas que inspiram as iniciativas do governo mencionadas anteriormente precisam repercutir efetivamente na formação inicial e continuada para poderem repercutir na atuação dos professores.

Partindo dessas considerações, o presente artigo tem como objetivos apresentar e discutir as implicaçōes da incorporação de práticas de letramento crítico na formação inicial de professores de línguas estrangeiras. Na próxima seção, comentarei alguns exemplos de lacunas entre o que se concebe no âmbito das políticas governamentais para o ensino de línguas e o que ocorre na sala de aula do ensino regular. Em seguida, apontarei algumas rotas para a formação inicial em LE, tomando como referência as concepções de multiletramento e, especialmente, a de letramento crítico.

\section{Notas dissonantes}

O descompasso entre o que se idealiza para o ensino da língua materna e das línguas estrangeiras, por meio dos programas criados pelo MEC e da definição de parâmetros/orientações para a Educação Básica, e o que efetivamente acontece na prática, se faz evidente de diferentes maneiras. Para 
ilustrar, vale a pena mencionar os resultados da pesquisa realizada por Silva (2008) sobre o uso de livros didáticos de alfabetização considerados bons pelo PNLD. A pesquisadora constatou que essas obras bem qualificadas, quando adotadas pela escola, costumam ser adaptadas por alguns professores que, por preferirem os métodos tradicionais, procuram adequar os livros a seus próprios valores e experiências. Sendo assim, embora o livro didático adotado tenha passado por um rigoroso processo de avaliação fundamentado nas teorias de letramento, os professores continuam pautando-se em concepçōes tradicionais de aprendizagem de leitura e escrita ao alfabetizar. A questão aqui não é discutir a melhor forma de ensinar/aprender a ler e escrever, mas sim demonstrar que a seleção e adoção de um livro não garantem a mudança da prática docente.

Com relação à LE, também se verificam notas dissonantes. Por exemplo, afirma-se, na apresentação do Guia de Livros Didáticos: PNLD 2011 - Língua Estrangeira, ${ }^{1}$ que é sempre importante lembrar que lugar de aprender LE é na escola de Educação Básica (BRASIL, 2010, p. 11). A necessidade de fazer uma afirmação tão enfática se dá certamente pelo fato de que "a língua inglesa como língua estrangeira tem sido vista como uma 'disciplinaproblema"” (MONTE MÓR, 2010, p. 577). Baseada em pesquisas, Monte Mór comenta as "crenças" ou "percepçôes" acerca do ensino/aprendizagem dessa língua na escola pública:

Essas crenças ou percepções revelam que alunos, pais de alunos, professores, enfim, envolvidos no ensino público acreditam que a escola de educação básica não se constitui o lugar no qual se aprende a língua inglesa; ou de que esse idioma só tem aprendizado eficaz fora da escola, na maioria das vezes em cursos de idiomas.

Essa opinião quanto ao lugar adequado para estudar inglês - a LE ensinada há mais tempo nas escolas - parece estender-se agora também ao espanhol, cuja oferta tornou-se obrigatória no Ensino Médio, conforme a lei $\mathrm{n}^{\circ}$ 11.161/2005 e, infelizmente, algumas secretarias estaduais de educação, ao contratarem cursos particulares de idiomas para ministrar aulas de LE aos alunos da escola pública, têm não só dado um mau exemplo, mas também colaborado para a difusão e reiteração das crenças comentadas por Monte Mór.

O Guia citado também afirma que o livro didático de LE selecionado "deve dar ao aluno condiçōes de aprender a ler, escrever, ouvir e falar na língua

${ }^{1}$ Doravante referido apenas como Guia. 
estrangeira” (BRASIL, 2010, p. 11). Entretanto, sabemos que ainda é muito presente a tradição do ensino de LE centrado na leitura em detrimento das outras habilidades. Isso se dá por vários fatores, dentre eles:

- a ênfase dada à preparação para o vestibular e, ultimamente, para o ENEM. Como esses exames objetivam avaliar a capacidade do aluno de ler e entender pequenos textos em LE, os planos de curso são elaborados quase exclusivamente para que o estudante, ao concluir o Ensino Básico, possa alcançar esse fim, não havendo preocupação em focalizar as demais habilidades;

- a falta de condições para trabalhar as habilidades orais. Os professores normalmente apontam as turmas grandes e a falta de aparelhos para reprodução de som e imagem, especialmente nas escolas públicas, como os principais fatores que inviabilizam ou dificultam a realização de atividades de compreensão e produção oral;

- a persistência de uma concepção de língua como sistema. Embora muitos professores já há alguns anos busquem planejar seus cursos a partir de temas, situações ou funções, o que poderia ensejar o desenvolvimento das outras habilidades (falar, ouvir, escrever) sem relegar a gramática a segundo plano, o ensino continua centrado em tópicos gramaticais e em exercícios estruturais. Desse modo, é ainda frequente a leitura de textos com a finalidade principal ou exclusiva de ilustrar o uso de tempos verbais, pronomes, adjetivos etc. e de vocabulário.

$\mathrm{Na}$ verdade, a concepção de linguagem como sistema não resiste apenas no ensino de LE, revela-se igualmente persistente no ensino de língua materna, interferindo no desenvolvimento de competências e capacidades. Por isso, ao comentar o relatório da 8 a edição do ENEM, em 2005, que evidencia os resultados insatisfatórios alcançados pelos candidatos, Rojo (2009, p. 33) observa:

[...] a escola - tanto pública como privada, neste caso - parece estar ensinando mais regras, normas e obediência a padróes linguísticos que o uso flexível e relacional de conceitos, a interpretação crítica e posicionada sobre fatos e opiniōes, a capacidade de defender posições e de protagonizar soluçôes, apesar de a "nova" LDB já ter doze anos.

A discussão em torno dessas incongruências, embora não seja recente, ainda não se esgotou. Vem à tona com frequência, trazendo novas contribuições para o debate sobre a pertinência de um ensino de LE na escola focado na leitura e sobre os prós e contras de um ensino centrado na gramática, ou centrado em temas, funçôes ou atos de fala. Há, contudo, outras 
dissonâncias à vista, talvez mais sérias e complexas no momento, porque começaram a ser detectadas e pesquisadas há poucos anos: aquelas que resultam das mudanças socioculturais e epistemológicas produzidas na era digital.

Segundo Lankshear e Knobel (apud MONTE MÓR, 2009, p. 181), as novas linguagens e tecnologias geraram um novo modo de construção do conhecimento, configurando uma "epistemologia digital" traduzida no uso de processos mentais que requerem maior capacidade de criação, em oposiçãa a uma "epistemologia convencional", baseada na reprodução de modelos.

Por outro lado, Kress (2006) chama a atenção para a mudança de uma era de domínio da escrita para uma era de domínio da imagem, o que, por sua vez, implica outras mudanças: do livro (ou impressão em papel) para a tela; do mundo narrado para o mundo retratado; da lógica da sequência dos elementos no tempo (uma palavra depois da outra) para a simultaneidade; da imagem que antes aparecia na página subordinada à lógica da escrita, para a escrita que agora aparece na tela submetida à lógica da imagem. Considerando essas mudanças, Cassany (2006, p. 9) sugere que já não sabemos o que é um livro e questiona se foi o livro que se tornou um objeto obsoleto ou se, simplesmente, lemos de outro modo, com tela e teclado.

A escola, indo na contramão, não está conseguindo sequer que os alunos alcancem um bom nível de capacidade leitora em exames baseados ainda na epistemologia convencional. Conforme o relatório do PISA 2009, ${ }^{2}$ por exemplo, quase metade dos alunos brasileiros tirou no máximo nota 2 na prova de leitura. Sendo assim, cabe indagar como seria com a leitura de textos produzidos segundo a lógica da imagem.

Ao mesmo tempo em que se constata uma defasagem entre as concepções de educação e de linguagem subjacentes aos PCN, às OCEM e a outras iniciativas do MEC, como o PNLD, por exemplo, e sua implementação na sala de aula, também se vislumbra o distanciamento cada vez maior entre o que se ensina/aprende na sala de aula e as novas competências requeridas pela sociedade digital, necessárias para atuar no mundo além dos muros da escola.

Identificar os descompassos nos leva a tentar encontrar suas possíveis causas: onde e por que os caminhos - da teoria e da prática, da escola e do mundo, do que se ensina e do que é preciso aprender - se desencontram?

\footnotetext{
2 O Relatório do Pisa está disponível em <http://www.oecd.org/document/61/ 0,3746,en_32252351_32235731_46567613_1_1_1_1,00.html>. Acesso em: 20 fev. 2012.
} 
Mendonça afirma que "o processo de formação de professores é um dos fatores que interfere na mudança de parâmetros para o ensino ou na manutenção destes" (2006, p. 223) e, sem dúvida, esse é o ponto chave. Dessa forma, se o ensino da escola básica tem sido posto em xeque, o ensino superior - no nosso caso específico, a formação de professores de LE - também deve passar por um processo de análise crítica e reestruturação. Afinal, se a LE "tem um valioso papel construtivo como parte integrante da educação formal", envolvendo "um complexo processo de reflexão sobre a realidade social, política e econômica, com valor intrínseco importante no processo de capacitação que leva à libertação [...]” (BRASIL-SEF, 1998, p. 41), é necessário que os professores estejam preparados para a tarefa que lhes cabe na Educação Básica e, mais do que isso, é preciso que eles próprios também sejam formados nessa perspectiva libertadora. Se a "comunicação mediada pelo computador oferece muitos exemplos de novos usos de linguagem e da premente necessidade de modi?car as concepções anteriores de linguagem, cultura e conhecimento" (BRASIL-SEB, 2006, p. 105), é indispensável que, na formação inicial, o futuro professor possa vivenciar e entender a modificação dessas concepçôes.

Em outras palavras, assim como a escola deve proporcionar o desenvolvimento das competências e capacidades necessárias ao aluno para integrar-se como cidadão na sociedade (globalizada, tecnológica, digital) e atuar com uma postura crítica, a universidade, em seus cursos de licenciatura, deve igualmente criar condiçõos para o desenvolvimento das competências e capacidades necessárias ao professor para atuar na sociedade como indivíduo reflexivo e crítico e para educar outros indivíduos.

\section{Possíveis rotas para (re)pensar formação do professor de LE}

O que significa preparar o futuro professor para educar no mundo contemporâneo? Para responder essa pergunta, precisamos uma vez mais olhar na direção da Educação Básica. Segundo Rojo, o ensino na escola deve contribuir para que o aluno "desenvolva certas competências básicas para o trato com as línguas, as linguagens, as mídias e as múltiplas práticas letradas, de maneira crítica, ética, democrática e protagonista" (ROJO, 2009, p. 119). Sendo assim, essa também deveria ser a meta da formação do professor de línguas.

Não se pode perder de vista, entretanto, que a licenciatura tem uma dupla perspectiva: o aluno aprende conteúdos, habilidades, procedimentos etc. e, ao mesmo tempo, deve aprender a ensinar o que aprendeu. Por essa razão, as disciplinas que compóem o currículo da licenciatura costumam estar 
divididas entre teóricas e práticas e, em alguns casos, ser ministradas em faculdades diferentes: na de Letras e na de Educação, respectivamente. Contudo, essa divisão acaba sendo contraproducente e ilusória, pois onde está a fronteira entre aprender para si mesmo e aprender para/a ensinar? Então, uma formação que pudesse integrar os conhecimentos, as disciplinas, tanto teóricas quanto práticas, não poderia prescindir de uma metodologia de ensino-aprendizagem que contemplasse, por exemplo, as diferentes formas de uso das linguagens (verbal, gráfica, plástica etc.) e das línguas (ler, ouvir, escrever, falar; as diversas variedades e registros), e a diversidade de mídias (sobretudo as digitais) e, ao mesmo tempo, promovesse a reflexáo sobre os modos como se aprende (ou se deve aprender) e como se ensina (ou se deve ensinar) no mundo atual.

Evidentemente, para se sintonizarem com as novas demandas educacionais, as licenciaturas deveriam passar por um processo permanente de análise e reestruturação, de modo que todas as disciplinas pudessem dialogar entre si e os docentes responsáveis por elas pudessem discutir sobre que tipo de formação querem propiciar aos futuros professores e, consequentemente, sobre as ações requeridas para concretizá-la. Sabemos, entretanto, que um processo assim depende de vários fatores e, mesmo havendo uma iniciativa real no sentido de realizar mudanças estruturais, estas não aconteceriam rapidamente. Desse modo, um primeiro e importante passo poderia ser que pelo menos cada docente responsável pelas disciplinas de LE na graduação procurasse (re)pensar seus cursos e suas aulas para proporcionar ao futuro professor experiências de ensinar e de aprender LE por meio da reflexão crítica sobre os modos atuais de usar a escrita e a leitura.

A seguir, veremos algumas das concepçôes teóricas subjacentes a essa tarefa. Como uma das ideias defendidas neste artigo é que os principais parâmetros para a formação do professor deveriam ser as funçōes requeridas dele na Educação Básica, tomarei como referência o Capítulo 3 - "Conhecimentos de Línguas Estrangeiras" - das OCEM (BRASIL-SEB, 2006) para tratar das concepções de multiletramento, como perspectiva que pode sedimentar o valor educacional da aprendizagem de uma LE, e de letramento crítico, como proposta de ampliação do trabalho de leitura a fim de contribuir para o desenvolvimento da percepção crítica dos alunos/futuros professores.

Segundo Gee, o letramento é entendido como

un conjunto de prácticas discursivas, es decir, como formas de usar la lengua y otorgar sentido tanto en el habla como en la escritura. Estas prácticas discursivas están ligadas a visiones del mundo específicas 
(creencias y valores) de determinados grupos sociales o culturales. Estas prácticas discursivas están integralmente conectadas con la identidad o consciencia de sí misma de la gente que las practica; un cambio en las prácticas discursivas es un cambio de identidad. (2004, p. 24)

Essa definição pode ser identificada com o modelo ideológico de letramento, em oposição ao modelo autônomo, ambos definidos por Street (1984; 2004). Enquanto o modelo ideológico chama a atenção para a relação intrínseca entre as práticas letradas e as estruturas de cultura e poder da sociedade, o modelo autônomo define o letramento como um processo cognitivo individual (e não, social), desvinculado de instituições, de contextos culturais e, como consequência, de relações de poder.

A opção por uma ou outra concepção de letramento no ensino/ aprendizagem na escola e também na licenciatura ${ }^{3}$ tem implicações. No âmbito educacional, o trabalho com a escrita e com a leitura privilegia normalmente gêneros textuais em que predominam sequências linguísticas expositivas, tais como seminários, verbetes, resumos de textos, relatos de experiências científicas (MARCUSCHI, 2008) e também a apresentação dos conteúdos em apostilas, em livros de caráter didático e na própria atuação do professor - as aulas expositivas -, os trabalhos para avaliação feitos pelos alunos, as perguntas e respostas das provas etc., ou seja, quase todas as atividades que envolvem o texto (oral e escrito) na sala de aula. Todas essas práticas, no entanto, são práticas escolares, ${ }^{4}$ cuja razão de ser se dá em função do lugar onde se produzem e, sendo assim, não se justificam em contextos que não estejam de algum modo ligados à escola.

Em decorrência dessa perspectiva, outras práticas letradas acabam não tendo lugar no espaço escolar. Na verdade, não se dá valor ao papel que a escrita tem fora desse espaço e se entende que o objetivo da educação formal (básica ou superior) se limita a desenvolver a capacidade de raciocínio lógico, análise, síntese, exposição, argumentação etc. Por essa razão, as habilidades relacionadas à produção e leitura de textos se restringem àquelas necessárias às práticas escolares. Nesse sentido, o letramento promovido pelas instituições de educação formal se enquadraria no modelo autônomo descrito por Street, pois

\footnotetext{
${ }^{3}$ Sempre que usar a palavra licenciatura, estarei fazendo referência à graduação em Letras/Línguas Estrangeiras.

${ }^{4}$ Sempre que usar as palavras escola e escolar estarei me referindo tanto à Educação Básica quanto à licenciatura.
} 
se dá de forma independente do contexto, enfatiza as técnicas e os aspectos cognitivos da leitura e da escrita em detrimento dos aspectos sociais, ignora outras práticas letradas e os contextos socioculturais em que estas se dão.

Se antes, com a adoção desse modelo, já eram muitas as formas de escrita e leitura não reconhecidas pela educação formal, com o avanço das tecnologias tornou-se ainda mais evidente a lacuna existente entre os mundos dentro e fora da escola. Antes esses mundos se distanciavam porque as propostas didáticopedagógicas se renovaram muito pouco nas últimas décadas enquanto mudaram significativamente os valores, os costumes, os hábitos, açôes como deslocar-se de um lugar pra outro, comunicar-se e relacionar-se com outras pessoas, divertir-se, informar-se etc., assim como as noçôes de tempo, espaço, velocidade, direitos, deveres, justiça etc. Com a chegada do computador, a distância se tornou ainda maior.

Segundo Manovich, a revolução gerada pelo computador é mais profunda do que as revoluçôes anteriores, provocadas pela imprensa, fotografia e televisão. Isso se dá porque "the computer media revolution affects all stages of communication, including acquisition, manipulation, storage, and distribution; it affects all types of media - texts, still images, moving images, sound, and spatial constructions" (2001, p. 19). Por essa razão, inclusive uma pessoa que não saiba usar um computador ou não o tenha presente fisicamente em suas atividades é de alguma forma afetada por ele, não só porque gráficos, imagens em movimento, sons, formas e textos se tornaram computáveis, ou seja, podem ser transformados em representações numéricas acessíveis pelo computador (MANOVICH, 2001, p. 25), mas também porque ações cotidianas simples, como pagar uma fatura ou retirar dinheiro do banco, são mediadas pela digitalização de dados. Portanto, o computador possibilitou que o universo de práticas letradas que se dão fora da escola se ampliasse consideravelmente, principalmente para as geraçôes que já nasceram no mundo digital e usam, além dos já tradicionais celulares e desktops, ebooks, tablets, ,iphones, ipads, ipods etc. como meios de ser e estar no mundo.

O surgimento de novas práticas letradas ou novos letramentos reforça a necessidade de diminuir a lacuna cada vez maior entre a forma como se lê e escreve na escola/academia e as formas como os estudantes usam a escrita e a leitura fora desse espaço. Ou seja, é necessário superar o modelo autônomo de letramento, supostamente neutro. Assumindo um modelo ideológico de letramento, ou letramento crítico, a educação pode caminhar em outra direção, pois passa a reconhecer que: 
- as práticas de escrita e leitura foram e são construídas socialmente e se vinculam a relações de poder;

- as formas como se usam a escrita e a leitura no cotidiano, fora da escola, constituem práticas letradas tão importantes quanto aquelas desenvolvidas na educação formal e, portanto, o letramento escolar é uma opção dentre outras;

- a ideologia perpassa toda e qualquer forma de letramento e, portanto, o letramento escolar não é neutro;

- a educação formal deve promover o multiletramento, ou seja, agenciar com igual relevância outras práticas letradas, além das tradicionais, e propiciar a reflexão crítica sobre os usos, valores e funções dessas práticas.

Embora o letramento crítico esteja associado obviamente às práticas de leitura e escrita, pode ser entendido como uma perspectiva educacional ou um modo de conceber a educação formal e suas finalidades. Essa perspectiva afeta não apenas os objetivos que se estabelecem para o trabalho com o texto na sala de aula, mas também e, principalmente, aos próprios objetivos que se definem para o ensino/aprendizagem da LE.

\section{Letramento crítico e formação de professores de LE}

As concepções de multiletramento e letramento crítico nos servem para fundamentar e justificar a proposta de que os professores de LE na licenciatura procurem (re)pensar seus cursos e suas aulas para possibilitar ao futuro professor experiências de ensinar e de aprender LE por meio da reflexão crítica sobre os modos atuais de usar a escrita e a leitura. O propósito desta seção é discutir o desenvolvimento dessa proposta baseado no letramento crítico.

Adotam-se aqui algumas premissas do letramento crítico formuladas por Cervetti, Pardales e Damico (2001, s. p.): o conhecimento não é natural nem neutro, mas sim ideológico, baseia-se nas regras discursivas de cada comunidade e, portanto, é sempre um conhecimento situado; do mesmo modo, a realidade não é passível de ser apreendida e descrita pela linguagem, com isenção de valores e intenções, ao contrário, a verdade é sempre relativa, matizada por pontos de vista, e deve ser compreendida dentro de um contexto determinado, em relação com os sujeitos envolvidos nas práticas letradas; os significados do texto (o que se escreve e também o que se fala) ultrapassam as prováveis intençôes do autor/locutor, visto que são sempre múltiplos, contestáveis, construídos social, histórica e culturalmente e perpassados por 
relações de poder. No âmbito educacional, o objetivo do letramento crítico é o desenvolvimento da consciência crítica. Assim, espera-se que "with critical consciousness as a prominent goal of literacy learning, students not only read texts critically, but they also become actors to transform society".

Pensar na relação entre as novas práticas letradas e a formação do professor de LE pressupóe considerar aspectos já amplamente destacados, mas cujo impacto para o ensino e a aprendizagem parece necessitar ainda de muita discussão, já que as açōes de ler e escrever requerem hoje outras habilidades além das que tradicionalmente são trabalhadas na educação formal. O hipertexto e a combinação do texto verbal com imagens, sons, ícones etc. contribuíram para que se modificassem os procedimentos de leitura. Passamos a mobilizar novas estratégias para o acesso, a seleção, o processamento e a interpretação das informaçôes. As habilidades mínimas necessárias para a leitura de textos impressos em papel se maximizam quando lemos na internet: olhamos em várias direçôes, rolamos a página para baixo e para cima, clicamos sobre um link, avançamos, voltamos ou não à página inicial e podemos seguir infinitamente essa trajetória imprevisível, pois não há última página e nem ponto final. $O$ percurso feito não é o mesmo da leitura de um livro, uma revista ou um jornal impressos, também não são os mesmos os modos empregados para percorrê-lo.

A escrita, por sua vez, fora do espaço escolar, prescinde quase completamente do papel, o que pode ser ilustrado com exemplos muito simples: já não é comum usar cadernetas para guardar telefones e endereços nem bloquinhos para anotar recados ou lembretes, as cartas pessoais e os telegramas já se tornaram obsoletos, formulários para tirar documentos ou solicitar serviços podem ser acessados e enviados por internet. Em suma, hoje a tela, seja do computador, do celular ou de outro aparelho, substitui o papel na maior parte das vezes em que precisamos registrar algo por escrito. Por conta do novo suporte e das ferramentas e recursos que ele proporciona, o conceito de escrita também se modificou e as mudanças ocorridas talvez sejam até mais radicais do que aquelas relacionadas à leitura.

A escrita já não se vincula à organização das palavras no papel e, no caso do texto informal, não depende mais da grafia integral de cada palavra, já que abreviaçôes e emoticons podem transmitir satisfatoriamente o que se quer dizer. Esses fatores nos levam a repensar os gêneros textuais com os quais devemos trabalhar na aula de LE, procurando transpor o muro que deixa fora do espaço escolar/acadêmico o modo como escrevemos no cotidiano. 
A possibilidade de dispor, no mesmo suporte em que se escreve, de recursos e ferramentas para deletar, copiar e colar, para destacar com negritos, sublinhados, itálicos, cores, diferentes tamanhos e tipos de fontes, para inserir gráficos, tabelas e imagens, para formatar o texto, revisar a ortografia, buscar sinônimos etc. ampliou e diversificou as habilidades - de caráter mais técnico - necessárias para produzir um texto. Por outro lado, o grande volume de informaçôes a que se tem acesso demanda outras competências, tais como a busca, seleção, processamento e organização das informaçóes relevantes, tarefas que se aliam à definição dos objetivos do texto a ser produzido, à capacidade de avaliar a credibilidade das fontes de pesquisa, de estabelecer a relevância dos dados e de usar esses dados para o desenvolvimento de ideias, conceitos e opinióes próprios. Sendo assim, deve fazer parte do letramento promovido pela escola e, consequentemente, pela licenciatura em LE o desenvolvimento de habilidades necessárias ao uso de ferramentas para editar textos - pois ter familiaridade com computadores não implica necessariamente dominar tais ferramentas - $\mathrm{e}$, sobretudo, o aprofundamento da leitura crítica como uma das condições para o posicionamento fundamentado e coerente na elaboração dos próprios textos.

Para finalizar, cabe ressaltar não só a variedade de gêneros discursivos que emergiram com a internet e que demandam formas diferentes de conceber $o$ texto escrito, como e-mails e blogs, e as novas formas de escrita coletiva, como as wikis, mas também práticas que, originariamente orais, passaram a se subordinar à escrita, como as "conversas" por chat e os relacionamentos por meio de redes sociais. É importante avaliar, então, como essas mudanças devem ser contempladas no âmbito da educação formal para redimensionar o seu papel na formação do professor.

A partir das considerações feitas, podemos tentar avaliar em que medida os novos modos de ler e escrever, usando a tela como suporte, interferem na maneira como se ensina e como se aprende a LE na formação inicial.

No caso do formador de professores que trabalha na licenciatura há mais de cinco anos, uma forma talvez simples de começar a reflexão é indagandose a si mesmo o que mudou nas suas aulas nesses últimos anos, incluindo o planejamento do curso, os conteúdos ensinados, os recursos utilizados, a dinâmica da sala de aula e as formas de avaliação. Se pouca coisa mudou, é sinal de que as novas práticas letradas ainda estão longe das aulas de LE na formação inicial. Por outro lado, se muitas coisas se modificaram, é necessário ponderar se as modificações são significativas: alteraram os modos de ensinar e de aprender a LE ou se tratou simplesmente de incorporar novas tecnologias de 
informação e comunicação (TIC) a velhas práticas? Como destacam Adell e Castañeda, "en demasiadas ocasiones intentamos 'encajar' las TIC sobre una estructura nacida y creada en otro tiempo y bajo supuestos diferentes y a veces contradictorios con los que subyacen a algunas de las nuevas tecnologias de las que hoy disponemos" (2010, s.p.).

Outra forma de abordar o tema é pensar se os novos modos de escrever e ler têm sido minimamente incorporados às nossas aulas de LE, por meio de: ${ }^{5}$

- contato com os alunos através de e-mail;

- disponibilizaçáo de materiais didáticos e recebimento de trabalhos por meios eletrônicos (e-mail, Google.docs, plataformas Moodle ou Teleduc etc.);

- incentivo ao uso das ferramentas de autocorreção do Word (ou similares);

- orientação para o uso de buscadores de informação;

- sugestão de blogs, wikis, webquests etc. como recursos para aprender;

- inclusão de revistas, jornais e dicionários eletrônicos na bibliografia do curso;

- uso das ferramentas do Word (ou equivalentes) para a revisão dos textos dos alunos;

- orientação para a criação de blogs;

- atividades para a elaboração de mapas conceituais (fichas de leitura, organização do vocabulário em campos semânticos) com o uso de programas (p. ex., XMind);

- orientação para criação de arquivos MP3 como estratégia para o desenvolvimento da compreensão oral (p. ex., Audacity);

- discussão de temas por meio de fóruns na internet;

- desenvolvimento da produção oral por meio da criação de vídeos (p. ex., Moviemaker).

Podemos ainda aprofundar a reflexão por meio das seguintes perguntas:

- De que maneira as mudanças de suporte para a escrita e a leitura afetam a formação inicial do professor de LE?

- As novas práticas letradas podem modificar a forma como se ensina e se aprende a LE?

${ }^{5}$ Listo aqui as ações que já foram integradas na minha prática docente. 
- Em que momento a reflexão crítica sobre os novos modos de ler e escrever possibilitados pelo computador (a tela no lugar do papel) tem lugar nas aulas de LE?

A substituição do papel pela tela e todas as implicações decorrentes dessa mudança deveriam afetar de modo contundente a formação inicial de professores, porque pressupóem uma epistemologia que não se pauta mais em sequências pré-estabelecidas, linearidade e segmentação - aspectos estes que estão na base da forma clássica de planejar um curso -, mas sim numa "lógica de redes" (CASTELLS, 2006, p. 108), ou numa "aprendizagem invisível" (COBO; MORAVEC, 2011, p. 29), que se dá de maneira contínua, imprevisível, informal e, obrigatoriamente, por meio da ação/criação, ou seja, não se aprende sobre, aprende-se fazendo, criando.

Tanto o planejamento de aulas como a elaboração de materiais didáticos de LE se fundamentam em duas perguntas básicas: O que e como ensinar/ aprender? Os novos letramentos podem mudar significativamente as respostas dessas perguntas, pois trata-se de conceber o ensino/aprendizagem de LE de uma forma diferente da tradicional, reduzindo progressivamente as práticas constituídas por conteúdos estandardizados (por exemplo: tópicos gramaticais sequenciados a partir do que supostamente é mais fácil para o mais difícil, regras para redigir textos argumentativos, descritivos etc.), ênfase em técnicas e habilidades de escrita e leitura relacionadas a textos veiculados em papel, aulas expositivas e centradas no professor.

É importante ressaltar que passar a conceber de outra maneira o ensino/ aprendizagem de LE, incorporando as novas práticas letradas, não significa deixar de fazer tudo que se fazia antes, ou desconsiderar todos os conteúdos gramaticais ou não - ensinados/aprendidos até então. Trata-se, sim, de avaliar a importância e a funcionalidade daquilo que tanto professores como alunos vão fazer na sala de aula e fora dela (planejamento e tarefas), como há tanto já se vem discutindo. No entanto, a discussão não está mais centrada nas vantagens e desvantagens de usar este ou aquele método, ou de ensinar gramática a partir de uma perspectiva mais estrutural ou mais comunicativa.

A discussão agora, como foi visto, se dá em torno de um dado concreto: um grande número de práticas que envolvem escrita e leitura é mediada pelo computador. Muitas dessas práticas acontecem na área do trabalho e determinam a redefiniçãa de competências que se exigiam antes no desempenho das funções, outras vêm gradativamente integrando-se ao nosso cotidiano como formas de entretenimento ou simplesmente porque 
determinados serviços passaram a funcionar de outro jeito, por exemplo, reclamaçôes e pedidos de cancelamento são feitos normalmente por telefone e lançados num sistema de dados. Essa realidade não pode mais ser ignorada na formação inicial de professores e, se não for por outros motivos, deve ser então pelo fato de que todos os alunos em idade escolar matriculados hoje na Educação Básica nasceram na era digital e a maioria teve/tem acesso a aparelhos eletrônicos antes mesmo de entrar na escola. Ora, o que isso significa? Que para esses alunos deve ser muito difícil ler e escrever do jeito que a escola quer, seguindo a lógica do texto no papel, sobretudo porque não consideram útil nem necessário usar a escrita dessa forma, como ressalta Cassany:

Al margen de que al principio los niños se alfabeticen sobre todo en la escuela, muchos aprenden a usar la escritura para hacer cosas distintas fuera del entorno educativo. Se trata de prácticas privadas, personales, informales, flexibles o libres y voluntarias, que aprenden por su cuenta y que resultan mucho más interesantes para ellos que las formas escolares de leer y escribir, que podemos calificar como estándar, formal, rígido e impuesto. (s.d., p. 12)

Essa razão bem como as outras são suficientes para que as práticas na escola e na formação de professores se modifiquem, incorporando de fato as tecnologias e propiciando, ao mesmo tempo, a reflexáo crítica sobre o acesso a elas, seu uso e suas funçōes na sociedade atual e, especificamente, no próprio contexto.

Assim, se considerarmos que a internet tem potencial educativo, que normalmente faz parte da rotina da maior parte dos alunos da Educação Básica e dos futuros professores, e que "los usuarios se apropian de las nuevas tecnologias y las reinventan” (COBO; MORAVEC, 2011, p. 15), como podemos integrar as tecnologias nas aulas para que alunos e futuros professores se apropriem da LE, reinventem formas de aprender e ensinar e, ao mesmo tempo, tenham uma visão crítica sobre as implicações sociais e culturais das novas formas de escrita e leitura?

Certamente, não é fácil nem para nós formadores, nem para os futuros professores, abandonar a visão tradicional de ensinar/aprender LE. Afinal, não se desfazem repentinamente os condicionamentos derivados de anos de escolarização, por isso, a mudança acaba se dando de forma lenta e progressiva. Contudo, parece fundamental que o ponto de partida seja privilegiar a escrita e a leitura na tela, estimulando o uso do computador e da internet, inclusive na sala de aula quando for possível. A partir daí, tanto os conteúdos como a dinâmica das aulas são automaticamente redefinidos. 
Alguns objetivos, critérios e desdobramentos dessa proposta:

- Ensinar/aprender LE por meio das tecnologias.

$\mathrm{O}$ uso das tecnologias neste contexto se refere a usar instrumentos, recursos e ferramentas que, de alguma forma, envolvam a escrita e/ou a leitura na tela, dando lugar, na sala de aula, às novas práticas letradas.

Exemplo: indicar aos alunos/futuros professores que acedam a um determinado site (na LE estudada, por exemplo: www.saludinforma.es) e pedir que verifiquem as informações que constam na página inicial, como essas informaçôes estão organizadas, se há como identificar quem criou o site, se é institucional ou não, por que foi criado, a que público se destina etc. Pedirlhes que, a partir dessa página: façam o percurso que quiserem durante $15 \mathrm{ou}$ 20 minutos, identifiquem depois as outras páginas que abriram, expliquem o que motivou suas escolhas, apontem qual a relação que há entre elas, contem resumidamente o que leram ou que acharam mais interessante, as informaçōes relevantes etc. Podem também estabelecer critérios para avaliar o site ou compará-lo com outros que conhecem.

- Desenvolver as habilidades necessárias para o uso dessas tecnologias.

Entre essas habilidades incluem-se as relacionadas ao uso da LE, ao uso do computador (ou outros instrumentos), à navegação na internet e aquelas relacionadas especificamente à tarefa a ser realizada.

Por exemplo, as habilidades requeridas para executar as tarefas sugeridas no item anterior englobam não só os procedimentos mais simples de acessar um site e clicar sobre um link para abrir outra página, mas também estratégias para localizar as informaçoes solicitadas, identificar como e por que as páginas desse site se relacionam. Além dessas, as habilidades de leitura e expressão oral na LE.

A prática sugerida permite ainda discutir os conceitos de hipertexto e multimodalidade, e aprofundar conhecimentos de gramática e de vocabulário.

- Promover a reflexão crítica sobre as novas práticas letradas.

A reflexão proposta deve se fundamentar nas premissas do letramento crítico apontadas anteriormente, dentre elas, que os textos são sempre situados, ou seja, são produzidos num dado contexto, com autoria, individual ou coletiva (mesmo que não esteja explícita), e veiculam valores e visōes de mundo, por essa razão, não são neutros. 
Por exemplo, a prática sugerida no primeiro item pode ser ampliada por meio de uma discussão acerca do que motivou a seleção de determinados links em detrimento de outros, do que determinou a definição dos critérios para avaliar o site etc. As escolhas derivam de interesses pessoais, do que cada um considera relevante ou não, estão relacionadas a conhecimentos e experiências anteriores, em determinados contextos, por isso, são escolhas marcadas por fatores socioculturais e impregnadas de valores.

A reflexão crítica abarca diversos aspectos. Abaixo, menciono alguns deles:

- a relação entre as práticas letradas e os contextos: o que significa escrever e ler para aprender, no contexto acadêmico; quais são os usos e funçōes daquilo que se lê e que se escreve nesse contexto; em que se diferencia ler e escrever na sala de aula, por exemplo, e ler e escrever em outros contextos; quais fatores dão origem a essas diferenças; como as práticas letradas acadêmicas podem contribuir para o ensino da LE na Educação Básica;

- os usos e funçôes das tecnologias: como as tecnologias interferem em nossas ações cotidianas, no trabalho, no lazer, na aprendizagem, na relação com os outros etc.; quem tem acesso às tecnologias e quem não tem; como e por que as tecnologias facilitam o ensino/aprendizagem de LE; por que é importante usar as tecnologias no contexto escolar; quais mudanças sociais e culturais as tecnologias provocaram nos últimos anos (no mundo, no país, no próprio contexto); que pessoas e que lugares foram mais afetados por essas mudanças;

- os usos e funçōes das novas formas de ler e escrever: quais são as habilidades necessárias para ler e escrever na tela; em que ler e escrever na tela difere de ler e escrever em outro suporte; quais habilidades devem ser desenvolvidas para escrever e ler usando o computador e a internet; quais mudanças ocorreram nas práticas de escrita e leitura desenvolvidas na escola nos últimos anos;

- as práticas específicas desenvolvidas na sala de aula: quais eram seus objetivos e se foram alcançados; quais habilidades elas ajudaram a desenvolver ou aperfeiçoar; se podem ser desenvolvidas na Educação Básica; o que elas propiciaram aprender.

As práticas realizadas na sala de aula são muito importantes e não se pode prescindir da reflexão crítica. Ela pode ser feita também a partir da discussão de algumas questôes provocadoras, como as sugeridas por Manovich, por exemplo: What do cultural interfaces - web pages, CD-Rom titles, computer games - look the way they do? Why do designer organize computer data in certain 
ways and not in others? Why do they employ some interface metaphors and not others? (2001, p. 71). O autor aborda também outros temas que podem ser igualmente interessantes para a discussão: o mito da interatividade - nós não somos realmente livres para fazer escolhas de percurso na internet porque temos de seguir associações pré-programadas; o indivíduo da sociedade da informação se engaja em mais atividades durante um dia típico; trabalho e lazer estão nas mesmas interfaces; o espaço físico e o espaço virtual se confundem.

A integração efetiva das tecnologias na formação inicial do professor passa necessariamente pela discussão dessas e de outras questôes que permitam desenvolver uma perspectiva crítica com relação às novas práticas letradas.

Os exemplos dados nesta seção são amostras muito simples do que se pode fazer. O desafio que se impõe é pensar em como os novos modos de escrever e ler podem fazer parte do ensino/aprendizagem da LE.

\section{Considerações finais}

As concepções de educação e de linguagem subjacentes aos $\mathrm{PCN}$, às OCEM e aos critérios de avaliação do PNLD não se fazem sentir nas aulas da Educação Básica. Do mesmo modo, a escola parece estar cada vez mais distante de propiciar aos alunos o desenvolvimento das habilidades requeridas pelos novos modos de escrever e ler, decorrentes da substituição do papel pela tela como suporte da escrita.

Investir em novas práticas na formação inicial de professores pode contribuir significativamente para que ocorram mudanças relevantes na escola. Assim, a proposta defendida aqui é que os professores de LE na licenciatura procurem (re)pensar seus cursos e suas aulas para possibilitar, ao futuro professor, experiências de ensinar e de aprender LE por meio da reflexão crítica sobre os modos atuais de usar a escrita e a leitura. Essa proposta prevê a incorporação efetiva das tecnologias no ensino/aprendizagem da LE e destaca a importância de discutir questōes sobre as implicaçōes sociais e culturais das novas práticas letradas.

\section{Referências}

ADELL SEGURA, J.; CASTAÑEDA QUINTERO, L. Los entornos personales de aprendizaje (PLEs): una nueva manera de entender el aprendizaje. In: ROIG VILA, R.; FIOTUCCI, M. (Ed.). Claves para la investigación en innovación y calidad educativas. La integración de las tecnologias de la información y la comunicación y la interculturalidad en las aulas. Alcoy: Marfil - Roma TRE Universita degli Studio, 2010. 
BRASIL. Guia de Livros Didáticos: PNLD 2011 - Língua Estrangeira. Brasília: Ministério da Educação, Secretaria de Educação Básica, 2011. Disponível em: <http://www.fnde.gov.br/index.php/pnld-guia-do-livro-didatico >. Acesso em: 20 fev. 2012.

BRASIL. Lei $N^{o}$ 9.394, de 20 de dezembro de 1996. Disponível em: <http:// www.camara.gov.br>. Acesso em: 20 fev. 2012.

BRASIL-SEB. Orientaçôes curriculares para o ensino médio. Linguagens, códigos e suas tecnologias. Conhecimentos de Línguas Estrangeiras; Conhecimentos de Espanhol. Brasília: MEC, Secretaria de Educação Básica, 2006, p. 85-124; p. 127-164. Disponível em: <http://www.portal.mec.gov.br/seb/arquivos/pdf/ book_volume_01_internet.Pdf >. Acesso em: 20 fev. 2012.

BRASIL-SEB. Parâmetros curriculares nacionais: Ensino Médio. Brasília: MEC, Secretaria de Educação Básica, 2000. Disponível em: <http://portal.mec.gov.br/ seb/arquivos/pdf/14_24.pdf>. Acesso em: 20 fev. 2012.

BRASIL-SEF. Parâmetros curriculares nacionais: terceiro e quarto ciclos do ensino fundamental: língua estrangeira. Brasília: MEC, Secretaria de Ensino Fundamental, 1998.

CASTELLS, M. A sociedade em rede. 4 ed. São Paulo: Paz e Terra, 2000.

CASSANY, D. Prácticas letradas contemporáneas: claves para su desarrollo. (s.d.) Disponível em: <http://www.leer.es/wp-content/uploads/webcast/documentos/ practicas_letradas/presen tacion_DanielCassany.pdf>. Acesso em: 20 fev. 2012. CASSANY, D. Tras las líneas. Sobre la lectura contemporánea. Barcelona: Anagrama, 2006.

CERVETTI, G.; PARDALES, M. J.; DAMICO, J. S. A Tale of Differences: Comparing the Traditions, Perspectives, and Educational Goals of Critical Reading and Critical Literacy. Reading Online, 4(9). Disponível em: <http:// www.readingonline.org/articles/art_index.asp?HREF=/articles/cervetti/ index.html>. Acesso em: 20 fev. 2012.

COBO, C.; MORAVEC, J. W. Aprendizaje invisible. Hacia una nueva ecología de la educación. Barcelona: Laboratori de mitjans interactius / Publicacions i Edicions de la Universitat de Barcelona, 2011. (Col.lecció Transmedia XXI)

GEE, J. P. Oralidad y literacidad: de el pensamiento salvaje a ways with words. In: ZAVALA, V.; NIÑO-MURCIA, M; AMES, P. (Ed.). Escritura y sociedad. Nuevas perspectivas teóricas y etnográfica, 2004 [1986]. p. 23-55.

KRESS, G. Literacy in the New Media Age. London: Routledge, 2006. 
MANOVICH, L. The language of new media. Cambridge: The MIT Press, 2001. MARCUSCHI, A. M. Produção textual, análise de gêneros e compreensão. São Paulo: Parábola Editorial, 2008.

MENDONÇA, M. Análise linguística no ensino médio: um novo olhar, um outro objeto. In: BUNZEN, C.; MENDONÇA, M. (Org.). Português no ensino médio e formação do professor. São Paulo: Parábola Editorial, 2006. p. 199-226. MONTE MÓR, W. A formação de professores e alunos na sociedade digital: políticas e práticas educacionais no ensino-aprendizagem de línguas estrangeiras. In: DALBEN, A. I. F. et al. (Org.). Convergências e tensões no campo da formação e do trabalho docente. Belo Horizonte: Autêntica, 2010. p. 577-594. (Coleção Didática e Prática de Ensino)

MONTE MÓR, W. Foreign Languages Teaching, Education and the New Literacies Studies: Expanding Views. In: GONÇALVES, G. R. et al. (Org.). New Challenges in Language and Literature. Belo Horizonte: Faculdade de Letras da UFMG, 2009. p. 177-188.

MONTE MÓR, W. Linguagem tecnológica e educação. Em busca de práticas para uma formação crítica. In: SIGNORINI, I.; FIAD, R. S. (Org.). Ensino de língua. Das reformas, das inquietações e dos desafios. Belo Horizonte: Editora UFMG, 2012. p. 171-190.

ROJO. R. (Org.). A prática de linguagem em sala de aula. Praticando os PCNs. São Paulo: EDUC; Campinas: Mercado de Letras, 2000.

ROJO. R. Letramentos múltiplos: escola e inclusão social. São Paulo: Parábola Editorial, 2009.

SIGNORINI, I.; FIAD, R. S. Apresentação. In: (Org.). Ensino de lingua. Das reformas, das inquietações e dos desafios. Belo Horizonte: Editora UFMG, 2012. p. 9-15.

SILVA, C. R. Formas de usos dos novos livros de alfabetização: por que os professores preferem os métodos tradicionais? In: COSTA VAL, M. G.; MARCUSCHI, B. (Org.). Livros didáticos de língua portuguesa. Letramento e cidadania. Belo Horizonte: Ceale; Autêntica, 2008. p. 185-203.

STREET, B. Los nuevos estudios de literacidad. In: ZAVALA, V.; NIÑO-MURCIA, M.; AMES, P. (Ed.). Escritura y sociedad. Nuevas perspectivas teóricas y etnográficas, 2004 [1993]. p. 81-107

STREET, B. Literacy in Theory and Practice. Cambridge: Cambridge University Press, 1984.

Recebido em 15/03/2012. Aprovado em 04/10/2012. 